\title{
A EDUCAÇÃO DE JOVENS E ADULTOS NO PANORAMA DA GARANTIA DO DIREITO
}

Fabiana Leal Nascimento. Mestranda em Educação para Ciências e Matemática. Instituto Federal de Educação, Ciência e Tecnologia de Goiás. Especialista em Educação Profissional e

Tecnológica pelo Instituto de Educação, Ciências e Tecnologia do Piauí. Graduada em Licenciatura Plena em Matemática pela Universidade Estadual do Piau fabiana.nascimento@ifma.edu.br

Viviane Ferreira Furtado. Mestra em Educação no Programa de Mestrado Profissional para Ciências e Matemática/IFG/Câmpus Jataí/ Graduada em Letra Português pela Universidade Federal de Goiás/ Especialista em Orientação Educacional pela Universidade Salgado de Oliveira. Atua como Professora Português do quadro Permanente do Magistério Público ffviviane@hotmail.com

\begin{abstract}
RESUMO: Este artigo objetiva apresentar como as políticas públicas, descritas nos documentos oficiais, regulamentam a manutenção do direito à formação para o trabalho e para o exercício da cidadania aos jovens e adultos excluídos do processo de ensino regular. Para tanto, faz uma breve descrição da origem da escola, seguida de uma sucinta exposição sobre a Educação de Jovens e Adultos garantida na Constituição Federal, nas duas Leis de Diretrizes e Bases da Educação Nacional e nos Planos Nacionais de Educação. Aborda uma retomada do estudo do processo histórico-cultural de ensino-aprendizagem e comenta algumas das características necessárias à formação de profissionais da educação, na busca por contribuir com o aprimoramento deste nível de ensino e garantir uma formação emancipatória aos sujeitos desta modalidade educacional. Os resultados demonstram a possibilidade de resgate do direito ao exercício da cidadania, mas reafirmam a necessidade de continuar com as mobilizações e com os debates em defesa de uma educação igualitária que inclua esta classe historicamente marginalizada nos documentos vindouros como, por exemplo, numa próxima versão do projeto Pátria Educadora.
\end{abstract}

Palavras-chave: Educação de jovens e adultos. Ensino-aprendizagem. Documentos oficiais.

\section{YOUTH AND ADULT EDUCATION IN THE PERSPECTIVE OF THE RIGHT WARRANTY}

ABSTRACT: This article aims to present how public policies, described in official documents, regulate the maintenance of the right to education for work and citizenship to excluded young people and adults from the regular educational process. Therefore, this article briefly describes the origins of school, followed by a short presentation on Youth and Adult Education guaranteed by the Brazilian Federal Constitution, the two laws of Directives and Bases of National Education and the National Education Plans. It addresses a revival of the study on the historical-cultural process of teaching and learning, as well as discusses some of the necessary features for the training of education professionals, aiming to contribute to the improvement of this level of teaching and to ensure an emancipatory education for subjects of this educational modality. The results show the possibility of redeeming the right to citizenship, but reaffirm the need to continue with the mobilizations on this topic and the debates in 
V.13, n. 1: 2017

defense of an egalitarian education that may include, in future documents, this historically marginalized class, such as in a next version of the Educator Homeland project.

Key-words: Youth and adults education. Teaching and learning. Official documents.

\section{Introdução}

A garantia do Estado Democrático de Direito contido na Constituição Federal $(\mathrm{CF})$, de 1988 tem como ponto de partida ações que consideram a educação como assunto principal entre todas as demandas sociais da nossa nação (BRASIL, 2010). Segundo a Lei de Diretrizes e Bases da Educação Nacional-LDB (BRASIL, 1996) a educação é direito de todos os membros de uma sociedade, no documento não há uma declaração de segregação ou exceção, nem de priorização de classes. Porém, as sucessivas políticas de governo tem apresentado uma descontinuidade nas medidas aplicadas para a garantia ao acesso e à permanência de jovens e adultos na escola. Muitas delas não asseguravam sua exequibilidade com a mudança de governos, e muitas vezes, dentro de um mesmo período de governo.

A Emenda Constitucional no 59 de 2009 teve um papel importante na ruptura de uma sequência de decisões em curto prazo, pois, a partir dela, os planos de educação adquiriram uma validade de dez anos, tornando-se articuladores dos sistemas de educação (BRASIL, 2014) bem como na garantia do direito à “educação básica obrigatória e gratuita dos 4 (quatro) aos 17 (dezessete) anos de idade, assegurada inclusive sua oferta gratuita para todos os que a ela não tiveram acesso na idade própria” (BRASIL, 2009) .

O Plano Nacional de Educação (PNE) 2001-2010, aprovado pelo Projeto de Lei $n^{\circ}$ 10.172, de 09/01/2001, deveria ser desdobrado em planos decenais. Como um plano de Estado e não de governo, evidenciava uma obrigação, com as futuras gerações e representava "o sonho de uma lei" que responsabilizasse os municípios, os Estados e a União e, com a energia de seus idealizadores, transformar esse sonho em uma realidade. Para isso, o PNE buscava ações incorporadas com os três níveis de governo, formulando um entrelaçamento intergovernamental. Nessa direção:

O PNE traz o desafio da articulação para a oferta educacional de maneira integrada e colaborativa. Para concretizar-se como Política de Estado que extrapola os tempos das gestões governamentais, precisa estar vinculado aos planos estaduais, do Distrito Federal e municipais de Educação, além de servir de referência para a elaboração dos Planos Plurianuais nas diferentes esferas de gestão. As metas são nacionais, portanto, todos têm compromisso com cada uma delas (BRASIL, 2014). 
V.13, n. 1: 2017

Historicamente, a construção da Educação de Jovens e Adultos (EJA), no Brasil, foi marcada por políticas emergenciais, compensatórias, de práticas aligeiradas e carregadas das marcas do assistencialismo, segundo Mariotti (2000). Ainda hoje a garantia de condições de permanência e de oferta igualitária de educação de qualidade não se constitui uma realidade. De acordo com Machado (2013) as situações de fracasso escolar produzem marcas que afetam profundamente a identidade e ferem a autoimagem do (a) aluno (a) jovem e adulto (a).

Nesse sentido, o trabalho aqui apresentado propõe-se a debater como as políticas públicas regulamentam a manutenção do direito à formação para o trabalho e para o exercício da cidadania aos jovens e adultos, nos documentos oficiais como: a CF, as LDB e os PNE, além da versão preliminar do documento Pátria Educadora.

\section{Objetivos}

Este estudo tem por objetivo geral investigar como as políticas públicas, descritas nos documentos oficiais, regulamentam a manutenção do direito à formação para o trabalho e para o exercício da cidadania aos jovens e adultos que, de alguma maneira, foram excluídos do processo de ensino regular e não puderam concluir os estudos. Para tanto, propõe uma retomada do estudo do processo histórico-cultural de ensino-aprendizagem e almeja discutir algumas das características necessárias à formação de profissionais da educação para este nível de ensino.

\section{Metodologia}

Para atingir aos fins propostos, este artigo foi caracterizado como uma pesquisa bibliográfica, ancorada em Gil (2008). Contém uma breve explanação, na contextualização, sobre o surgimento da escola, seguida de uma sucinta exposição sobre a EJA no país e uma concisa discussão sobre a política educacional nacional, no atual PNE. Para tal, apropriamonos de Saviani (2007) e (2014). Para tratar da responsabilidade dos profissionais que atuam na EJA, lançamos mão de Arroyo (2008) e Vieiro (2007); e diversos autores sustentam o trabalho aqui desenvolvido, dentre eles, Geraldi (2010) para discorrer sobre formação de professores; Brandão (2010) e Haddad (2003) sobre as obrigações do Estado.

\section{Contextualização histórica}


V.13, n. 1: 2017

Segundo Saviani (2007, p. 154), “A essência do homem é um feito humano. É um trabalho que se desenvolve, se aprofunda e se complexifica ao longo do tempo: é um processo histórico". Segundo o autor, desde a Antiguidade a divisão social em classes modificou a relação do indivíduo com o trabalho e com o modo de produção escravista. Nesse período, surgiu a diferenciação na educação: para a classe proprietária, a chamada educação dos homens livres, e para a outra classe uma educação dos escravos e serviçais. A escola foi institucionalizada para atender a classe dominante e favorecer funções de liderança militar e política.

Com o surgimento do modo de produção capitalista a relação trabalho/educação sofreu uma nova determinação na estrutura da sociedade passando a pautar-se por laços sociais, assim:

[...] o domínio de uma cultura intelectual, cujo componente mais elementar é o alfabeto, impõe-se como exigência generalizada a todos os membros da sociedade. $\mathrm{E}$ a escola, sendo o instrumento por excelência para viabilizar o acesso a esse tipo de cultura, é erigida na forma principal, dominante e generalizada de educação. Esse processo assume contornos mais nítidos com a consolidação da nova ordem social propiciada pela indústria moderna no contexto da Revolução Industrial (SAVIANI, 2007, p.158).

Assim, observa-se que a Revolução Industrial correspondeu a uma Revolução Educacional ao edificar na escola a forma dominante da educação, ligando-a, de algum modo, ao mundo da produção. Deste modo, "aprender a ler, escrever e contar, e dominar os rudimentos das ciências naturais e das ciências sociais constituem pré-requisitos para compreender o mundo em que se vive" SAVIANI, 2007, p.160).

No Brasil, a primeira LDB, aprovada em 20 de dezembro de 1961, atendia a interesses privados argumentando manter o direito das famílias de eleger o tipo de educação que deveria ser dado aos seus entes e combatendo o que consideravam como formas de monopolizar o ensino. O mesmo também pode ser percebido no contexto da construção do segundo PNE, já que os problemas foram grandes, pois atualmente os mecanismos de mercado interferem na esfera pública (SAVIANI, 2014). Nesse contexto, observa-se que:

[...] o movimento dos empresários vem ocupando espaço nas redes públicas via Undime e Consed, nos Conselhos de Educação e no próprio aparelho de Estado, como o ilustram as ações do Movimento "Todos pela Educação". É assim também que grande parte das redes públicas, em especial as municipais, vem dispensando os livros didáticos distribuídos gratuitamente pelo MEC e adquirindo os ditos "sistemas de ensino" como "Sistema COC", "Sistema Objetivo", "Sistema Positivo", "Sistema Uno", "Sistema Anglo" etc. com o argumento de que tais "sistemas" lhes permitem aumentar um pontinho nas avaliações do IDEB (SAVIANI, 2014, p. 2). 
V.13, n. 1: 2017

A política educacional brasileira desde o final da ditadura, em 1985, até os dias de hoje se apresenta com características de filantropia, por considerar que a educação é um problema de toda a sociedade e não propriamente do Estado. De protelação, pelo constante adiamento do enfrentamento do problema ao fixar longos prazos para que cada proposta seja avaliada ou mesmo para que entre em vigor. As características passam de fragmentação à improvisação, por criar medidas como ementas constitucionais, decretos ou portarias, sem a análise previa de sua necessidade ou correlação com as medidas anteriores (SAVIANI, 2014). Como se a educação fosse uma equação resulta empiricamente na: "precarização geral da educação em todo o país visível na rede física, nos equipamentos, nas condições de trabalho e salários dos profissionais da educação, nas teorias pedagógicas de ensino e aprendizagem, nos currículos e na avaliação dos resultados" (SAVIANI, 2014, p. 5).

Ao considerarmos que um indicador é sempre uma prévia do que se pretende alcançar, voltaremos a atenção para as expectativas das metas e estratégias, no atual PNE, referentes à Educação de Jovens e Adultos (EJA). Corroborando com os preceitos de Arroyo (2008, p. 221), verificamos que essa modalidade de ensino:

[...] tem sua história muito mais tensa do que a história da educação básica. Nela se cruzaram e cruzam interesses menos consensuais do que na educação da infância e da adolescência, sobretudo quando os jovens e adultos são trabalhadores, pobres, negros, subempregados, oprimidos, excluídos.

O assunto da EJA é tratado explicitamente no PNE nas metas 9 e 10 que, reciprocamente versam quanto a universalização da alfabetização, a redução do analfabetismo funcional e a articulação da EJA com a educação profissional. A meta 8 alcança o público de jovens e adultos uma vez que a mesma aspira "elevar a escolaridade média da população de 18 a 29 anos de modo a alcançar no mínimo 12 anos de estudo no último ano de vigência deste Plano" (BRASIL, 2014, p.11).

\section{A EJA no atual PNE}

O atrelamento entre os níveis manteve-se na edição do atual PNE, que em uma ação conjunta com a Organização das Nações Unidas para a Educação, a Ciência e a CulturaUNESCO, idealizam passos no sentido de que suas metas e estratégias se concretizem em todos os níveis do Estado e da sociedade, assegurando a coordenação de recursos públicos e a educação básica de qualidade para todos. É no artigo $2^{\circ}$ que as diretrizes do PNE são especificadas: 
I - erradicação do analfabetismo; II - universalização do atendimento escolar; III superação das desigualdades educacionais, com ênfase na promoção da cidadania e na erradicação de todas as formas de discriminação; IV - melhoria da qualidade da educação; V - formação para o trabalho e para a cidadania, com ênfase nos valores morais e éticos em que se fundamenta a sociedade; VI - promoção do princípio da gestão democrática da educação pública; VII - promoção humanística, científica, cultural e tecnológica do País; VIII - estabelecimento de meta de aplicação de recursos públicos em educação como proporção do Produto Interno Bruto - PIB, que assegure atendimento às necessidades de expansão, com padrão de qualidade e equidade; IX valorização dos (as) profissionais da educação; $X$ - promoção dos princípios do respeito aos direitos humanos, à diversidade e à sustentabilidade socioambiental (BRASIL, 2014).

Os alunos da EJA requerem atitudes imediatas para minimizar os processos de exclusão e de marginalização social. Ao observar o texto do PNE 2014-2024 quando, estabelece na nona meta as palavras "erradicar" e "analfabetismo", é necessário reportar-se aos dados da Pesquisa Nacional por Amostra de Domicílios/Instituto Brasileiro de Geografia e Estatística, PNAD/IBGE, de 2012 que revela na população de 15 anos ou mais um percentual de 8,7\% de analfabetos e 30,6\% de analfabetos funcionais, ou seja, as taxas elevadas para uma população estimada em 190.732.694 pessoas (IBGE, 2010). E, que ações de alfabetização e a continuidade na educação de jovens e adultos foram articuladas entre o poder público e a sociedade civil organizada, enquanto transcorriam dez longos anos de caminhos trilhados pelo PNE 2001-2010 e a implantação do novo PNE 2010 que foi aprovado em 25 de junho de 2014 (BRASIL, 2014)?

A meta dez, do atual PNE, traz a concepção de que a educação de jovens e adultos não pode se restringir a uma determinada fase da vida, nem mesmo se concentrar na aplicabilidade direta dos conhecimentos construídos na escola. Consolida a ideia de que o pleno exercício da cidadania, melhor aproveitamento do tempo e mais oportunidades de emprego estão associadas à capacidade de formação contínua, ou seja, de uma educação ao longo da vida (SENADO FEDERAL, 2001). Os programas educacionais criados referentes a essa meta ${ }^{1}$ são Mulheres Mil e o Programa Nacional de Acesso ao Ensino Técnico e ao Emprego-PRONATEC EJA.

\section{Da responsabilidade dos profissionais que atuam na EJA}

Vieiro (2007) descreve a “educação ao longo da vida” como princípio da Educação Popular e a necessidade de adequação curricular para a busca por totalidade de conhecimento. Essa perspectiva de formação de sujeito é fundamental nos processos educativos, especialmente

\footnotetext{
${ }^{1}$ Conforme o Portal do Governo Brasileiro. Disponível em: < http://pne.mec.gov >. Acesso em: jul. de 2015.
} 
V.13, n. 1: 2017

quando se trata de pessoas experientes, com histórias de vida distintas, mas, na maioria dos casos, igualmente difíceis. É necessário compreender que elas trazem consigo uma leitura de mundo constituída no decorrer de suas trajetórias. É preciso lhes oferecer novas formas de enxergar a própria história e de construir o futuro, de maneira que elas mesmas possam se considerar como sujeitas da própria vida.

Para Geraldi (2010, p. 32), “A leitura do mundo e a leitura da palavra são processos concomitantes na constituição dos sujeitos (...) em cada palavra a história das compreensões do passado e a construção das compreensões do presente se projetam como futuro". Assim, ele defende a aula como acontecimento, sob uma perspectiva que parte do vivido do aluno para gerar perguntas a partir das quais se possa desencadear o processo educativo, de maneira que o ensino não seja como a "aprendizagem do conhecido, mas como produção de conhecimentos que resultam, de modo geral, de novas articulações entre conhecimentos disponíveis”. Nesse sentido, a responsabilidade dos professores é grande, pois se espera que o professor seja um ser mais consciente de toda essa problemática e consiga, ainda que minimamente, oferecer um pouco mais de dignidade aos educandos.

\section{Obrigações do Estado na garantia do exercício da cidadania}

Ao buscar correlacionar este estudo com o que há de mais atual em termos de documentos oficiais, recorreu-se à versão preliminar do projeto "Pátria educadora: a qualificação do ensino básico como obra de construção nacional”, de 22 de abril de 2015 (BRASIL, 2015), publicado pela Secretaria de Assuntos Estratégicos. Constatou-se que nele, apesar do discurso de vanguarda pedagógica, sequer é mencionada a EJA. Valoriza apenas o ensino de Português e de Matemática, refere-se ao currículo, na perspectiva de segregação de classes, para os de origem sociocultural diferenciadas, conteúdos distintos na forma de sequência padrão e de "sequências especiais, para os alunos que enfrentem maior dificuldade ou que demonstrem maior potencial" (BRASIL, 2015, p.11). Assim, distancia-se por completo da garantia de erradicação de formas de discriminação propostas nas diretrizes do atual PNE, ao determinar que:

I - assegurem a articulação das políticas educacionais com as demais políticas sociais, particularmente as culturais; II - considerem as necessidades específicas das populações do campo e das comunidades indígenas e quilombolas, asseguradas a equidade educacional e a diversidade cultural (BRASIL, 2014, Art. 8, §1). 
V.13, n. 1: 2017

O artigo $1^{\circ}$, inciso II, da Constituição Federal de 1988, apresenta a cidadania como um dos fundamentos do Estado brasileiro. Com relação às obrigações do governo, para Brandão (2010, p.1), ele "tem o dever de estabelecer mecanismos de isonomia material aos economicamente necessitados. Significa que a desproporção de poder econômico em relação à parte hipossuficiente há de ser equalizada, conforme preconiza o art. 5o". Partindo dessa premissa, observa-se que ao longo da história, pode-se perceber que as pessoas analfabetas, ou com pouca escolaridade, que foram privadas do direito à escolarização, perderam uma importante ferramenta: o acesso ao saber sistematizado que é produzido pela humanidade. Segundo Haddad (2003), as pessoas que passam por processos educativos, em particular pelo sistema escolar, exercem melhor sua cidadania, pois, têm melhores condições de realizar e defender os outros direitos humanos como: saúde, segurança, moradia, meio ambiente, participação política e outros. O referido autor cita duas formas de manifestar a luta pela manutenção dos direitos dos cidadãos, a busca pela cidadania ativa e a procura pela cidadania passiva. Na primeira encontra-se a peleja diária dos cidadãos por garantir direitos individuais e coletivos, que se diferencia da segunda, que visa assegurar os direitos outorgados pelo Estado. Nesse sentido, na cidadania ativa os princípios da democracia podem ser fortalecidos com a manutenção do respeito aos direitos civis, políticos, econômicos, sociais, culturais e ambientais. 
V.13, n. 1: 2017

\section{Considerações finais}

Não diferentemente das outras modalidades de ensino, para que a EJA contribua com a sociedade, seus sujeitos devem ir além do básico ler e escrever. A clientela, marcada por especificidades, precisa ter a oportunidade de resgatar o direito à condição de atuação política, com capacidade de crítica e de formulação de propostas a serviço da cidadania e da transformação social. Atualmente, observa-se que a nossa Carta Magna, a LDB e o PNE estabelecem a garantia do direito igualitário à formação para a cidadania e para o trabalho, porém, na prática, muito ainda há o que aprimorar e paira no ar a preocupação com os documentos vindouros, como é o caso da versão final, caso haja, do projeto Pátria Educadora, no sentido de evitar que apenas continuem efetuando a equação citada por Saviani (2014). Apesar das dificuldades, não diferentemente dos demais períodos históricos, compete, de forma geral, à sociedade e, em particular, aos professores as tarefas de zelar para não retroceder no caso das conquistas já adquiridas em forma de leis e para reivindicar melhorias no processo de ensino-aprendizagem com o objetivo de garantir o direito ao exercício da cidadania aos jovens e adultos excluídos do processo de ensino regular. 
V.13, n. 1: 2017

\section{Referências:}

ARROYO, Miguel G. A educação de jovens e adultos em tempos de exclusão. In. : VÓVIO, Cláudia Lemos e IRELAND, Timothy Denis. Construção coletiva: contribuições à educação de jovens e adultos. 2. ed. Brasília: Unesco, MEC, RAAAB, 2008. (Coleção Educação para Todos; 3), p. 221-230.

BRANDÃO, Fernanda Holanda de Vasconcelos. Dignidade da pessoa humana e cidadania: Princípios fundamentais e essenciais para o acesso à Justiça. In: Âmbito Jurídico, Rio Grande, XIII, n. 75, abr. 2010. Disponível em: < http://www.ambitojuridico.com.br/site/index.php?n_link=revista_artigos_leitura\&artigo_id=7538 $>$. Acesso em jul. 2015.

BRASIL, Carta-Compromisso pela Garantia do Direito à Educação de Qualidade - Uma convocação aos futuros governantes e parlamentares do Brasil, 2010. Disponível em: < http://www.campanhaeducacao.org.br/?idn=99 >. Acesso em 23 mar. 2015.

Emenda Constitucional n 59, de 11 de novembro de 2009.

. Lei n⿳ 9.394, de 20/12/21996. Estabelece as diretrizes e bases da educação nacional. São Paulo: Editora do Brasil S/A.

. Planejando a próxima década: conhecendo as 20 metas do Plano Nacional de Educação, 2014.

. Secretaria de Assuntos Estratégicos da Presidência da República. Pátria Educadora: A qualificação do ensino básico como obra de construção nacional. Versão preliminar. Brasília, 22 de abril de 2015.

GERALDI, W. G. A aula como acontecimento. São Carlos, Pedro \& João Editores, 2010.

GIl, Antônio Carlos. Métodos e técnicas de pesquisa social. 6. ed. - São Paulo: Atlas, 2008.

HADDAD, Sérgio. Educação de Jovens e Adultos, a promoção da Cidadania Ativa e o desenvolvimento de uma consciência e uma cultura de paz e direitos humanos. 2003. Disponível em:<

http://fait.revista.inf.br/imagens_arquivos/arquivos_destaque/2CaAw1nnUL9zQGT_2014-416-17-7-18.pdf. > Acesso em jul. 2015.

IBGE, Disponível em:

http://www.ibge.gov.br/home/estatistica/populacao/censo2010/default.shtm. Acesso em: jul. 2015.

MACHADO, Maria Margarida e OLIVEIRA, Edna de Castro. O analfabetismo e tantos outros desafios da educação de jovens e adultos no PNE 2011-20120. In.: PINO, Ivani Rodrigues; ZAN, Dirce Djanira Pacheco e. (Org.) Plano Nacional de Educação (PNE): questões desafiadoras e embates emblemáticos. Brasília: Inep, 2013, p. 129-143. 
V.13, n. 1: 2017

MARIOTTI, Humberto. As paixões do ego: complexidade, política e solidariedade. São Paulo. Palas Athena, 2000.

OBSERVATÓRIO DO PNE, Metas do PNE. Disponível em < http://www.observatoriodopne.org.br/metas-pne >. Acesso em jul. 2015.

SAVIANI, Dermeval. Entrevista concedida ao Portal Anped em 07 Abr. 2014. Disponível em: $<$ http://portal anped.verkn.com.br/news/entrevista-com-dermeval-saviani-pne $>$. Acesso em abr. 2015.

Trabalho e educação: fundamentos ontológicos e históricos. Revista Brasileira de Educação v. 12, n. 34, jan./abr. 2007. Disponível em: < http://www.redalyc.org/articulo.oa?id=27503412 >. Acesso em abr. 2015.

SENADO FEDERAL, Plano Nacional de Educação. Brasília: Senado Federal, UNESCO. 2001. Disponível em: < http://unesdoc.unesco.org/images/0013/001324/132452porb.pdf >. Acesso em abr. 2015.

VIERO, Anésia. Educação de jovens e adultos: da perspectiva da ordem social capitalista à solução para emancipação humana. In.: GUSTSACK, Felipe; VIEGAS, Moacir Fernando e BARCELOS, Valdo (Orgs.). Educação de jovens e adultos: saberes e práticas. Santa Cruz do Sul: EDUNISC, 2007. 